\title{
ENSURE RESOURCE OPTIMIZATION TEKNOLOGI INFORMASI MENGGUNAKAN COBIT 5
}

\author{
Sarmini ${ }^{*}$, Palupi Pandanarum ${ }^{2}$ \\ Program Studi Sistem Informasi, Universitas Amikom Purwokerto, Jawa Tengah ${ }^{1,2}$ \\ e-mail: sarmini@amikompurwokerto.ac.id ${ }^{1}$,palupipandan@gmail.com ${ }^{2}$
}

\begin{abstract}
Abstrak
Departemen TI menghadapi beberapa kendala antara lain kurangnya alokasi anggaran bagi organisasi / lembaga dalam memenuhi infrastruktur TI, dan infrastruktur yang ada tidak sesuai dengan strategi bisnis organisasi. Dapat disimpulkan bahwa infrastruktur TI merupakan salah satu sumber permasalahan dalam pengelolaan TI. Mengelola sumber daya TI sesuai dengan standar yang berlaku untuk pemanfaatan TI di organisasi / lembaga merupakan salah satu poin penting agar pemanfaatan TI mencapai tujuan perusahaan. Tujuan dari penelitian ini adalah untuk menilai sejauhmana proses optimasi sumber daya TI di Universitas Amikom Purwokerto. Kerangka COBIT digunakan untuk proses penilaian; Kerangka ini memiliki beberapa manfaat. TI dapat diciptakan dan dioptimalkan serta terwujudnya keseimbangan manfaat dan tingkat risiko serta penggunaan sumber daya TI. Dari hasil evaluasi tersebut, saat ini tingkat kapabilitas proses Ensure Resource Optimization di Universitas Amikom Purwokerto berada pada level 2 (Managed Process). Hal ini menunjukkan bahwa Universitas Amikom Purwokerto telah melaksanakan, merencanakan, memantau dan menyesuaikan proses optimalisasi sumber daya TI dan produk yang dihasilkan telah terdefinisi, dikendalikan, dan dipelihara dengan baik. Proses optimalisasi sumber daya TI di Universitas Amikom Purwokerto dipastikan sesuai dengan target level yang diharapkan, sehingga perlu dibuat SOP untuk mencapai persyaratan level 3 sesuai dengan rekomendasi yang diberikan.
\end{abstract}

Kata kunci : Sumber Daya; Teknologi Informasi; Tingkat Kapabilitas; COBIT 5

\begin{abstract}
The IT department faces several obstacles, including a lack of budget allocation for organizations $/$ institutions in fulfilling IT infrastructure, and the existing infrastructure not in accordance with the organization's business strategy. It can be concluded that the IT infrastructure is a source of problems in IT management. Managing IT resources in accordance with applicable standards for IT utilization in organizations / institutions is one of the important points for IT utilization to achieve company goals. The purpose of this study is to assess the extent of the optimization process of IT resources at the University of Amikom Purwokerto. The COBIT framework is used for the assessment process, this framework has several benefits. IT can be created and optimized and the realization of a balance of benefits and levels of risk and use of IT resources. From the results of the evaluation, currently the capability level of the Ensure Resource Optimization process at Amikom Purwokerto University is at level 2 (Managed Process). This shows that the University of Amikom Purwokerto has implemented, planned, monitored and adjusted the optimization process of IT resources and the resulting products have been well defined, controlled, and maintained. The process of optimizing IT resources at Amikom Purwokerto University is ensured to be in accordance with the expected target level, so it is necessary to make SOPs to achieve level 3 requirements according to the recommendations given.
\end{abstract}

Keywords : Resources; Information Technology; Capability Level; COBIT 5 


\section{PENDAHULUAN}

Ketika organisasi mampu menerjemahkan visi, misi dan tujuan organisasi ke dalam rencana bisnis dan rencana Teknologi Informasi (TI), maka penerapan TI tentunya akan menguntungkan bagi organisasi. Keunggulan kompetitif dalam persaingan bisnis menjadi nilai bagi organisasi/institusi ketika strategi TI dan strategi bisnis selaras. Untuk menciptakan keselarasan ini, tata kelola TI harus dapat mengoptimalkan penggunaan TI yang ada dalam organisasi [1]. Keuntungan optimal dapat dicapai dengan tata kelola TI yang baik [2].

Salah satu tanggung jawab besar Departemen TI dalam pengelolaan TI di suatu organisasi/institusi adalah mereka harus bisa memaksimalkan penggunaan TI yang sudah diimplementasikan. Namun terdapat beberapa permasalahan yang kompleks terkait tata kelola infrastruktur TI seperti alokasi anggaran yang tidak memadai untuk infrastruktur TI yang membuat organisasi/institusi harus memenuhinya. Permasalahan lainnya adalah pengelolaan TI yang tidak optimal akibat infrastruktur TI dan strategi bisnis organisasi yang tidak selaras.

Untuk mencapai tujuan perusahaan dalam memanfaatan TI, sumber daya TI harus dikelola sesuai dengan standar yang berlaku untuk memanfaatan TI di organisasi/lembaga. Model manajemen diperlukan dalam mengelola sumber daya TI. Hal tersebut dapat menjadi anteseden sesuai dengan kebijakan dan sasaran organisasi/lembaga serta dapat pula digunakan sebagai alat ukur dalam mengatasi permasalahan yang terjadi di lembaga [3].

Untuk mencapai tujuan suatu organisasi atau perusahaan diperlukan peningkatan sumber daya yakni sekumpulan metode atau upaya untuk meningkatkan aktivitas dari kesiapan syarat berupa manusia, proses, dan teknologi yang harus digunakan secara praktis dan tepat guna [4]. Terdapat COBIT framework yang dapat digunakan sebagai framework agar sumber daya TI dapat dioptimalkan sesuai standar. COBIT juga dapat menyeimbangkan ekspektasi dan peningkatan derajat ancaman serta pemanfaatan sumber daya [5].

Dalam kerangka COBIT 5, EDM04 adalah salah satu proses yang berfokus pada pengoptimalan sumber daya TI - yakni proses mengoptimalkan sumber daya. Fokusnya adalah menilai proses pengoptimalan sumber daya di perusahaan dan meyakinkan bahwa kepentingan sumber daya perusahaan terwujud secara maksimal, anggaran TI dimaksimalkan, memungkinkan adanya kenaikan laba, dan kesiapan untuk transformasi di masa kemudian. Pendekatan penilaian diri digunakan untuk proses penilaian. Tahapan tersebut meliputi penentuan ruang lingkup proses, penentuan tingkat kapabilitas tahap pertama, penentuan kemampuan tahap kedua hingga kelima, pencatatan dan ringkasan tingkat kapabilitas, terakhir perencanaan perbaikan proses.

Beberapa penelitian terkait optimalisasi sumber daya TI menggunakan kerangka kerja COBIT 5 telah dilakukan seperti riset yang dilakukan oleh [6], penelitian tersebut mengimplementasikan tolok ukur manajemen sumber daya TI untuk mendukung tata kelola TI di instansi pemerintahan. Evaluasi pengelolaan sumber daya TI juga dilakukan pada PT. Infomedia Nusantara dengan mengukur 4 sub domain di dalam COBIT 5 [4]. Penelitian lainnya terkait optimalisasi sumber daya TI dilakukan pada sebuah lembaga pendidikan untuk mengoptimalisasikan pemanfaatan sumber daya baik di sisi brainware, software dan hardware) [7]. Dan penelitian lainnya yang serupa adalah peningkatan sumber daya Sistem Informasi Manajemen Jembatan Timbang pada Dinas Perhubungan 
Komunikasi dan Informatika Provinsi Jawa Tengah untuk meningkatkan efektifitas pelayanan [8].

Memang telah banyak penelitian yang terkait dilakukan namun optimalisasi sumber daya TI untuk menciptakan sebuah tata kelola TI yang baik pada sebuah perguruan tinggi belum banyak ditemui. Maka dari itu, pada riset yang akan dilakukan adalah untuk mengukur proses optimasi sumber daya TI di Universitas Amikom Purwokerto dengan tujuan untuk menilai sejauh mana proses optimalisasi sumber daya TI oleh departemen terkait untuk mendukung tujuan PT.

\section{TINJAUAN PUSTAKA}

\subsection{COBIT (Tujuan Pengendalian untuk Informasi dan Teknologi Terkait)}

COBIT adalah kerangka kerja yang diterbitkan oleh ISACA (Asosiasi Audit dan Kontrol Sistem Informasi) [5]. COBIT menyediakan tata kelola TI melalui ranah, mekanisme, sasaran, aktivitas, tingkat kemampuan, dan bentuk yang rasional dan terarah. Ini mendukung peningkatan TI yang terkait dengan investasi, serta memastikan pemberian fasilitas dan menyediakan cara atau tolok ukur pengukuran yang praktis untuk tujuan manajemen. Sasaran fundamental COBIT adalah membuat manajemen senior mengetahui dan mengatur ancaman yang terkait dengan TI [9].

\subsection{EDM04 - Pastikan Pengoptimalan Sumber Daya}

Proses EDM04 - Pastikan Pengoptimalan Sumber Daya, artinya memastikan kapabilitas dan persyaratan sumber daya organisasi seperti kesediaan orang, proses, dan teknologi untuk membantu sasaran organisasi secara praktis dengan anggaran maksimal, dan juga meyakinkan bahwa sumber daya perusahaan kebutuhan tercukupi secara maksimal, memungkinkan realisasi laba meningkat, serta ketersediaan untuk transisi di waktu yang akan datang [6].

\subsection{Penelitian Sebelumnya}

Penelitian sebelumnya terkait pengelolaan sumber daya TI telah dilakukan, yaitu pengelolaan sumber daya TI dalam mendukung tata kelola TI di instansi pemerintah. Kajian ini memiliki sasaran untuk mengoptimalkan tata kelola TI yang optimal untuk institusi pemerintah menurut perolehan penilaian e-Government Indonesia (PeGI) tingkat provinsi diakhir tahun 2013 dengan mengimplementasikan tolok ukur pengendalian sumber daya TI yang merujuk pada kerangka praktik terbaik COBIT 5 [6].

Penelitian selanjutnya terkait penilaian prasarana TI menggunakan framework COBIT 5 dan ITIL V3. Penilaian tata kelola diukur dengan maturity level tata kelola TI dengan mengaplikasikan 13 proses pada COBIT 5. Evaluasi yang dilakukan bertujuan agar dapat memenuhi kebutuhan infrastruktur TI, kinerja dan layanan TI yang baik akan didapatkan dengan infrastruktur yang memadai [10].

Penelitian selanjutnya yang telah dilakukan terkait dengan optimalisasi tata kelola TI dengan mengimplementasikan COBIT 5 di sekolah menengah, riset ini memiliki capaian yaitu untuk memperoleh perhitungan awal atas penggunaan tata kelola TI berbasis COBIT 5 dengan keadaan implementasi yang tengah beroperasi [11].

Penelitian lain yang telah dilakukan adalah mengevaluasi penyelenggaraan sumber daya teknologi informasi (IT Resource Management) dengan memanfaatkan kerangka kerja COBIT 5. Penelitian ini mengenai pemanfaatan TI dalam mencapai tujuan perusahaan. Evaluasi dilakukan dengan menganalisis tingkat kapabilitas, kemudian berdasarkan analisis capability level akan diberikan rekomendasi 
perbaikan pada masing-masing sub domain [4].

Penelitian selanjutnya yang telah dilakukan adalah membahas bagaimana kerangka kerja COBIT diterapkan untuk mengidentifikasi maturity level tata kelola TI. Tujuan dari riset ini adalah untuk menilai tata kelola TI dan mengukur maturity level tata kelola TI di Fasilkom Unwidha agar penerapan tata kelola TI dapat berlangsung efektif sehingga dapat memberikan layanan yang optimal dan meraih target perusahaan sesuai dengan yang diinginkan [12].

Bersumber pada telaah sebelumnya, menunjukkan perlunya suatu organisasi/lembaga/ perusahaan mengevaluasi tata kelola yang berkaitan dengan pengelolaan sumber daya TI untuk meyakinkan bahwa penggunaan TI dapat mendukung institusi/lembaga tersebut dalam menggapai tujuannya.

\section{METODOLOGI PENELITIAN}

Kerangka penelitian menjelaskan tahapan yang dikerjakan untuk mengerjakan penelitian yang dilakukan. Tahapan tersebut dapat dilihat pada kerangka penelitian berikut:

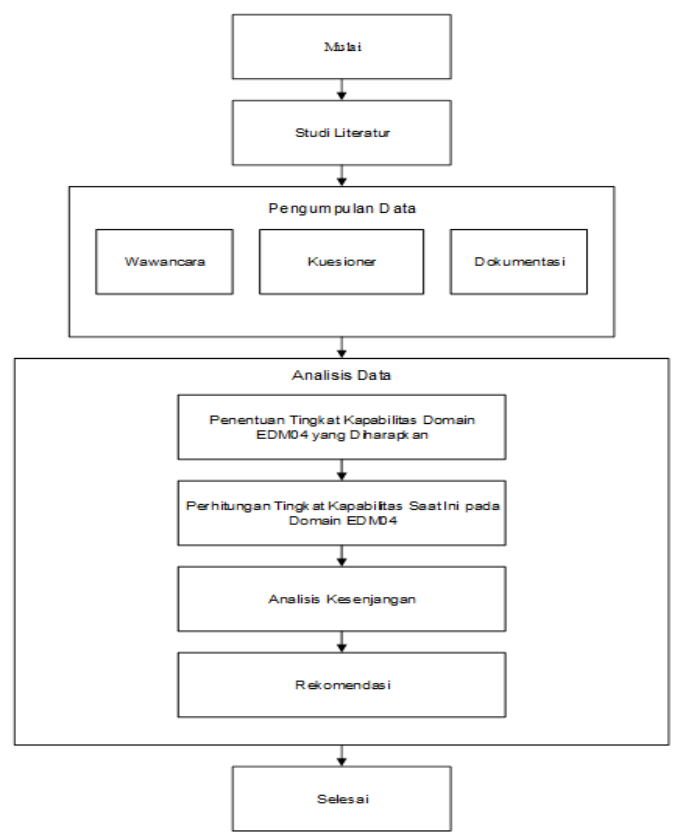

Gambar 1. Kerangka Penelitian

Sumber : Data yang diolah, Tahun 2020
Tahap-tahap yang dikerjakan dalam riset ini untuk menentukan capability level domain proses EDM04 - Memastikan Optimasi Sumber Daya berdasarkan pedoman COBIT 5 adalah sebagai berikut [13]:

1. Studi pustaka adalah proses pengumpulan semua keterangan yang disebar baik dari berbagai kepustakaan, buku, laporan, makalah, bahan konferensi dan data keterangan dari internet yang membantu objek penelitian dengan cara mengumpulkan dasar-dasar kaidah dan penelitian sebelumnya. Merujuk pada kaidahkaidah terkait COBIT 5 yang dirincikan secara ringkas sesuai dengan tingkat kebutuhan dalam penelitian, riset ini berfokus pada kaidah capability level yang termuat didalam kerangka kerja COBIT 5, domain proses EDM, sub domain EDM04.

2. Pengumpulan fakta yaitu pengumpulan fakta yang berkenaan dengan penelitian, melakukan penilaian kuantitatif capability level yang diperoleh dari proses asesmen langsung kepada pihakpihak yang terlibat dengan membuat checklist yang diambil dari template alat asesmen COBIT 5 dari ISACA.

- Interview, metode yang dikerjakan untuk menghimpun fakta dan data. Hasilnya akan disajikan sebagai data penunjang dari perolehan penilaian capability level untuk setiap prosesnya.

- Kuisioner pada riset ini disusun untuk menilai tingkat kapabilitas manajemen sumber daya TI yang sedang beroperasi di Universitas Amikom Purwokerto. Kuisioner yang disebarkan kepada informan adalah pernyataan tertulis, pernyataan yang dibuat merujuk pada framework sub domain COBIT 5 dari proses EDM04. 
- Dokumentasi digunakan untuk memperoleh keterangan dari prespektif subjek dengan menggunakan perangkat tertulis dan dokumen lain yang ditulis atau dibuat langsung oleh subjek yang berkepentingan.

3. Analisis data adalah analisis data yang terdiri dari analisis tingkat kemampuan sekarang, tingkat kemampuan yang diharapkan, dan telaah kesenjangan.

Ada enam tingkat kapabilitas yang dapat dicapai oleh setiap proses, yaitu:

0 Proses Tidak Lengkap; Proses tidak diterapkan atau tujuan gagal dicapai. Pada tingkat ini, tidak ada bukti perolehan sasaran proses yang teratur.

1 Proses yang Dilakukan - Proses yang dijalankan (satu atribut); menerapkan proses dan tujuan tercapai.

2 Proses yang Dikelola - Proses biasa (dua atribut); menjalankan proses secara teratur (merencanakan, memantau, dan menyesuaikan), dan menghasilkan produk yang ditentukan, dikendalikan, dan dipelihara dengan baik.

3 Proses yang Ditetapkan - Proses tetap (dua atribut); melaksanakan proses dengan menetapkan proses tertentu yang telah ditentukan, dan hasilnya dapat dicapai sesuai keinginan.

\section{Proses yang Dapat Diprediksi -}

Proses yang dapat diprediksi (dua atribut); menjalankan dan menentukan proses untuk memperoleh hasil proses yang diinginkan.

5 Mengoptimalkan Proses - Optimasi Proses (dua atribut);

memperbaiki proses secara terus menerus sehingga sasaran bisnis sekarang dan selanjutnya dapat tercapai.

4. Analisis capability level saat ini bersumber pada fakta dari perolehan tanya jawab dan survelience mengisi daftar periksa kuesioner kepada penyelenggara sumber daya TI di Universitas Amikom, Purwokerto.

5. Analisis kesenjangan tingkat kemampuan saat ini dengan tingkat kemampuan yang diharapkan. Dengan demikian dapat dilihat sejauh mana capaian yang harus diperoleh hingga tujuan organisasi terwujud.

Rekomendasi, setelah menghitung capability level dan gap analisis, tahap selanjutnya adalah menyusun pertimbangan tata kelola TI yang lebih praktis dan dapat memperoleh tingkat yang diharapkan sesuai dengan hasil perhitungan yang telah dikerjakan pada domain proses EDM04 yaitu memastikan optimasi sumber daya.

\section{HASIL DAN PEMBAHASAN}

\subsection{Perhitungan Tingkat Kemampuan} Saat Ini (As Is) Proses Domain EDM04 Memastikan Optimasi

\section{Sumber Daya.}

Proses pastikan optimasi sumber daya merupakan proses yang mengelola sumber daya TI (pegawai, proses dan teknologi) dan kapabilitas yang mencukupi sehingga dapat membantu tujuan perusahaan secara praktis dengan anggaran yang maksimal. Meyakinkan sumber daya yang diperlukan perusahaan tersedia secara maksimal, anggaran TI diminimalkan secara maksimal, serta meyakinkan kemungkinan penambahan laba dan kemauan untuk berubah di Tabel 1 menjelaskan rangkuman hasil perolehan tingkat beserta detail spesifik terkait proses penilaian ini sebagai berikut masa depan. 
Tabel 1 Ensure Resource Optimisation EDM04

\begin{tabular}{|c|c|c|c|c|c|c|c|c|c|c|}
\hline Tujuan & $\begin{array}{l}\text { Meyak } \\
\text { maksin } \\
\text { peluan } \\
\text { kemud }\end{array}$ & $\begin{array}{l}\text { kan sum } \\
\text { l, anggar } \\
\text { neningka } \\
\end{array}$ & $\begin{array}{l}\mathrm{r} \text { day: } \\
\text { TI d } \\
\text { ya keu }\end{array}$ & $\begin{array}{l}\text { ng di } \\
\text { an se } \\
\operatorname{gan} d\end{array}$ & kesi & $\begin{array}{l}\text { peru } \\
\text { ima } \\
\text { n ur }\end{array}$ & $\begin{array}{r}\text { ahaa } \\
\text { dat } \\
\text { uk t }\end{array}$ & $\begin{array}{l}\text { terc } \\
\text { uga } \\
\text { sfor }\end{array}$ & $\begin{array}{l}\text { upi } \\
\text { eyal } \\
\text { asi d }\end{array}$ & $\begin{array}{l}\text { ecara } \\
\text { nkan } \\
\text { masa }\end{array}$ \\
\hline \multirow{2}{*}{$\begin{array}{l}\text { Proses } \\
\text { Ensure } \\
\text { Resource } \\
\text { Optimisation }\end{array}$} & \multirow[t]{2}{*}{$\begin{array}{c}\text { Level } \\
0\end{array}$} & \multirow{2}{*}{$\begin{array}{l}\text { Level } \\
1\end{array}$} & \multicolumn{2}{|c|}{$\begin{array}{c}\text { Level } \\
2\end{array}$} & \multicolumn{2}{|c|}{$\begin{array}{c}\text { Level } \\
3\end{array}$} & \multicolumn{2}{|c|}{$\begin{array}{c}\text { Level } \\
4\end{array}$} & \multicolumn{2}{|c|}{$\begin{array}{c}\text { Level } \\
5\end{array}$} \\
\hline & & & $\begin{array}{l}\text { PA } \\
2.1\end{array}$ & $\begin{array}{l}\text { PA } \\
2.2\end{array}$ & $\begin{array}{l}\text { PA } \\
3.1\end{array}$ & $\begin{array}{l}\mathrm{PA} \\
3.2\end{array}$ & $\begin{array}{l}\text { PA } \\
4.1\end{array}$ & $\begin{array}{l}\text { PA } \\
4.2\end{array}$ & $\begin{array}{l}\text { PA } \\
5.1\end{array}$ & $\begin{array}{l}\text { PA } \\
5.2\end{array}$ \\
\hline $\begin{array}{l}\text { Rating } \\
\text { berdasarkan } \\
\text { presentase }\end{array}$ & $100 \%$ & $88,89 \%$ & $100 \%$ & $100 \%$ & $0 \%$ & $0 \%$ & & & & \\
\hline $\begin{array}{l}\text { Rating } \\
\text { berdasarkan } \\
\text { warna }\end{array}$ & & & & & & & & & & \\
\hline
\end{tabular}

Sumber: Data yang diolah, Tahun 2020

Rangkuman pengukuran proses Ensure Resource Optimisation pada level 1 diuraikan melalui tabel di bawah ini

Tabel 2 Ensure Resource Optimisation EDM04 Level 1 EDM04 Ensure Resource Optimisation

\begin{tabular}{|c|c|c|c|}
\hline $\begin{array}{l}\text { Governance } \\
\text { Practice }\end{array}$ & Outputs & Exist & Score \\
\hline \multirow{3}{*}{$\begin{array}{l}\text { EDM04.01 } \\
\text { Evaluate resource } \\
\text { management }\end{array}$} & $\begin{array}{l}\text { Guiding principle for allocation of resources } \\
\text { and capabilities }\end{array}$ & $\sqrt{ }$ & \multirow{3}{*}{$66,7 \%$} \\
\hline & Guiding principles for enterprise architecture & - & \\
\hline & Approved resources plan & $\sqrt{ }$ & \\
\hline \multirow{3}{*}{$\begin{array}{l}\text { EDM04.02 } \\
\text { Direct resource } \\
\text { management }\end{array}$} & Communcation of resourcing strategies & $\sqrt{ }$ & \multirow{3}{*}{$100 \%$} \\
\hline & $\begin{array}{l}\text { Assigned responsibilities for resource } \\
\text { management }\end{array}$ & $\sqrt{ }$ & \\
\hline & Principles for safeguarding resources & $\sqrt{ }$ & \\
\hline \multirow{2}{*}{$\begin{array}{l}\text { EDM04.03 } \\
\text { Monitor resource } \\
\text { management }\end{array}$} & $\begin{array}{l}\text { Feedback on allocation and effectiveness of } \\
\text { resources and capabilities }\end{array}$ & $\sqrt{ }$ & \multirow{2}{*}{$100 \%$} \\
\hline & $\begin{array}{l}\text { Remedial actions to address resource } \\
\text { management deviations }\end{array}$ & $\sqrt{ }$ & \\
\hline \multicolumn{3}{|c|}{ Average Score } & $88,89 \%$ \\
\hline
\end{tabular}

Sumber: Data yang diolah, Tahun 2020

1. Evaluasi Manajemen Sumber Daya

Proses evaluasi pengelolaan sumber daya di Universitas Amikom Purwokerto dinyatakan tidak lulus, karena hanya memperoleh skor $66,67 \%$ dengan rincian sebagai berikut:

a. Adanya pedoman pengalokasian sumber daya dan kapabilitas yang tertuang dalam SOP. b. Saat ini Universitas Amikom Purwokerto belum memiliki pedoman prinsip Arsitektur Perusahaan.

c. Rencanakan dan pilih sumber daya yang diperlukan, misalnya:

- Untuk sumber daya manusia, ini dilakukan dengan membuka loker atau outsourcing. 
- Untuk software, bisa membeli dari vendor atau dengan membangun sendiri.

2. Manajemen Sumber Daya Langsung Proses manajemen sumber daya langsung di Universitas Amikom Purwokerto dinyatakan lulus dengan skor 100\% karena:

a. Menyampaikan strategi sumber daya dalam bentuk pertemuan pemangku kepentingan secara berkala.

b. Penetapan bagian yang bertanggung jawab atas pengelolaan sumber daya.

c. Adanya pedoman dalam memelihara dan merawat sumber daya yang ada, disesuaikan dengan masing-masing bagian.

3. Memantau Manajemen Sumber Daya

Proses Memantau Manajemen Sumber

Daya di Universitas Amikom Purwokerto dinyatakan lulus dengan skor $100 \%$ karena:

a. Pemantauan dilakukan terhadap alokasi dan efektivitas pemanfaatan sumber daya dan kapabilitas yang ada, dengan cara: seperti membuat daftar kapabilitas masing-masing anggota staf untuk setiap divisi.

b. Melakukan pengecekan secara berkala terhadap fasilitas yang diberikan kepada staf seperti PC dan laptop.

c. Jika terdapat kelangkaan sumber daya, maka ada langkah untuk segera memenuhi kelangkaan tersebut dengan melakukan pengajuan keperluan sumber daya kepada atasan. Contoh:

- Karena kekurangan SDM, maka diserahkan ke bagian BKH.

- Untuk infrastruktur TI diserahkan ke bagian keuangan.

Dari hasil penilaian tingkat kapabilitas, proses EDM04 lolos dari level 1, karena proses ini kondisi tercapai sepenuhnya sebesar $88,89 \%$ maka pada proses ini dapat dilakukan perhitungan untuk level 2.

Berikut adalah tabel yang menjelaskan capaian Universitas Amikom Purwokerto untuk proses EDM04 di level 2.
Tabel 3 Performance Management EDM04

\begin{tabular}{|l|c|c|}
\hline 2.1 Performance Management \\
\hline Generic Practice & Exist & Score \\
\hline Identify the objectives & $\sqrt{ }$ & $100 \%$ \\
\hline $\begin{array}{l}\text { Plan and monitor the } \\
\text { performance }\end{array}$ & $\sqrt{ }$ & $100 \%$ \\
\hline $\begin{array}{l}\text { Adjust the } \\
\text { performance }\end{array}$ & $\sqrt{ }$ & $100 \%$ \\
\hline Define responsibilities & $\sqrt{ }$ & $100 \%$ \\
\hline $\begin{array}{l}\text { Identify and make } \\
\text { available }\end{array}$ & $\sqrt{ }$ & $100 \%$ \\
\hline Manage the interfaces & $\sqrt{ }$ & $100 \%$ \\
\hline \multicolumn{2}{|c|}{ Average Score } \\
\hline
\end{tabular}

Sumber: Data yang diolah, Tahun 2020

Tabel 4 Work Product Management EDM04

\begin{tabular}{|c|c|c|}
\hline \multicolumn{3}{|c|}{2.2 Work Product Management } \\
\hline Generic Practice & Exist & Score \\
\hline $\begin{array}{l}\text { Define } \\
\text { requirements for the } \\
\text { work products }\end{array}$ & $\sqrt{ }$ & $100 \%$ \\
\hline $\begin{array}{l}\text { fine the requirements for } \\
\text { cumentation and control }\end{array}$ & $\sqrt{ }$ & $100 \%$ \\
\hline $\begin{array}{l}\text { Identify, document and } \\
\text { control }\end{array}$ & $\sqrt{ }$ & $100 \%$ \\
\hline $\begin{array}{l}\text { Review and adjust work } \\
\text { products }\end{array}$ & $\sqrt{ }$ & $100 \%$ \\
\hline Average Score & & $100 \%$ \\
\hline
\end{tabular}

Sumber: Data yang diolah, Tahun 2020

Semua proses yang lulus sepenuhnya dari level 1 dipastikan lolos ke level 2 karena:

1. Pegawai Universitas Purwokerto telah bekerja sesuai dengan jabatan, tugas pokok dan fungsinya. Mereka sadar akan tujuan aktivitas yang mereka lakukan.

2. Penilaian kinerja seluruh karyawan dipantau oleh KPI.

3. Semua kegiatan yang telah disetujui dan akan dilaksanakan sudah memiliki capaian program, masukan, keluaran dan hasil. Dengan adanya KPI maka terjadi pengawasan dan pengendalian terhadap penyimpangan. 
4. Menentukan tanggung jawab atas setiap proses yang berjalan, baik dalam SOP, tugas dan wewenang pekerjaan, serta penugasan tidak tertulis oleh atasan.

5. Menyediakan semua sumber daya yang dibutuhkan untuk menjalankan aktivitas di dalam perusahaan, seperti komputer, dan memberi setiap karyawan 1 PC.

6. Menentukan hubungan dengan pihak lain dalam menjalankan setiap proses, baik dalam SOP maupun tertulis yang diajarkan oleh rekan kerja atau atasan.

7. Tentukan dokumen kerja apa yang seharusnya. Serta template dokumen dan lainnya.

8. Setiap pembuatan dokumen tertulis nama pengarang dan pemeriksa yang menyetujuinya yaitu atasan / pimpinan.

9. Untuk pengendalian arus keluar masuk dokumen harus melalui agenda yang akan dicatat atau diberi nomor indeks dan juga nomor revisi, agar dokumen di lingkungan Universitas Amikom Purwokerto terkontrol dengan baik.

10. Memberikan perubahan format dokumen sesuai kebutuhan.

Dari hasil penilaian tingkat kapabilitas, proses Ensure Resource Optimization berada pada level 2 dengan status 100\% tercapai sepenuhnya, namun di Universitas Amikom Purwokerto belum ada definisi proses dan proses penerapan berupa SOP terkait proses EDM04 yang mana adalah persyaratan untuk penilaian di level 3 .

\subsection{Tingkat Kemampuan yang Diharapkan dan Analisis Kesenjangan.}

Penilaian gap dilakukan untuk melihat seberapa besar gap antara target tingkat kapabilitas saat ini dengan kondisi yang diharapkan yaitu proses yang telah ditetapkan (level 3). Bersumber pada perhitungan tingkat kapabilitas pada EDM04 proses Ensure Resource Optimization yang telah dilakukan maka ikhtisar yang dapat dibuat adalah saat ini EDM04 tingkat kapabilitas proses Ensure Resource Optimization di Universitas Amikom Purwokerto berada pada level 2 (Managed Process) yang memiliki selisih 1 untuk mencapai level 3 (Proses Mapan) sebagai tingkat kapabilitas target yang diharapkan. Hal ini membuktikan bahwa proses-proses tersebut telah dilaksanakan dengan melakukan perencanaan, pemantauan dan penyesuaian serta menghasilkan produk yang telah ditentukan sebelumnya, serta mengontrol dan memeliharanya dengan baik.

\subsection{Rekomendasi}

Untuk mencapai target level kapabilitas suatu organisasi / lembaga, disarankan untuk membuat SOP guna mencapai level 3 persyaratan dalam proses Pastikan Pengoptimalan Sumber Daya, yaitu:

1. Proses Yang Mapan

Berisi keluaran untuk mempertahankan proses yang ada di dalam organisasi/lembaga dengan menyempurnakan SOP organisasi/lembaga, yang terdiri dari:

- Tentukan standarnya

Memberikan SOP proses di organisasi / lembaga.

- Tentukan susunan dan hubungan antar proses

SOP yang ada dijelaskan secara berurutan dan hubungan antar proses.

- Identifikasi peran dan kompetensi mengenali peran dan kemampuan yang dijalankan dalam setiap proses.

- Identifikasi prasarana dan lingkungan kerja yang diperlukan

Identifikasi infrastruktur dan bagian kerja yang diperlukan.

- Tentukan metode yang cocok

Buat metode untuk memeriksa kesesuaian dan efektivitas SOP. 
2. Proses Penerapan

Berisi keluaran terkait apakah SOP telah dilaksanakan dengan benar atau tidak di organisasi/lembaga, dipenuhi pada saat SOP diaudit, antara lain:

- Terapkan proses yang ditentukan

Proses yang telah ditetapkan disebarluaskan, SOP dipastikan berjalan dengan baik dan diverifikasi.

- Tetapkan dan komunikasikan peran, tanggung jawab, dan wewenang

Tentukan dan komunikasikan tugas, kewajiban dan kewenangan dalam menjalankan proses.

- Pastikan kompetensi yang diperlukan

Memastikan kompetensi karyawan sesuai dengan bidang pekerjaannya. Ada aktivitas untuk meyakinkan bahwa pegawai yang melaksanakan proses tersebut berpengalaman, jika tidak berpengalaman maka diberikan pelatihan.

- Memfasilitasi sumber daya dan petunjuk untuk mendukung kemampuan kerja

Mendukung kinerja setiap proses dengan kesiapan sumber daya dan petunjuk.

- Menyediakan infrastruktur proses yang memadai

Menyediakan infrastruktur yang memadai untuk melakukan proses tersebut.

- Kumpulkan dan analisis data

Mengidentifikasi, mengumpulkan dan menganalisis fakta yang berhubungan dengan kinerja proses yang akan dimanfaatkan sebagai pedoman untuk perbaikan yang berkesinambungan.

\section{KESIMPULAN}

Sesuai dengan hasil rerata capability level yang dilakukan pada domain proses EDM04 Ensure Resource Optimization, saat ini tingkat kapabilitas proses Ensure Resource Optimization di Universitas Amikom Purwokerto berada pada level 2
(Managed Process) dan mempunyai gap 1 untuk memperoleh level 3 (Proses yang Mapan) yang telah menjadi tingkat kapabilitas target yang diharapkan. Hal ini membuktikan bahwa proses-proses tersebut telah dilaksanakan dengan melakukan perencanaan, pemantauan dan penyesuaian serta menghasilkan produk yang telah ditentukan, dikendalikan dan dipelihara dengan baik.

Untuk meyakinkan proses optimalisasi sumber daya TI di Universitas Amikom Purwokerto sesuai dengan target level yang diharapkan, maka perlu dibuat SOP untuk mencapai persyaratan level 3 sesuai dengan rekomendasi yang diberikan.

\section{SARAN}

Untuk mencapai optimalisasi sumber daya TI sesuai dengan tujuan yang diharapkan, diperlukan pengelolaan sumber daya TI yang baik, sehingga pada penelitian selanjutnya dapat menambahkan proses penilaian tingkat kapabilitas pada proses domain APO07 Manage Resource.

\section{DAFTAR PUSTAKA}

[1] H. Purnomo, S. Fauziati, and W. W. Winarno, "Penilaian Tingkat Kapabilitas Proses Tata Kelola Teknologi Informasi Dengan COBIT 5 Pada Domain EDM (Studi Kasus di PT. Nusa Halmahera Minerals)," Knastik, pp. 69-75, 2016.

[2] A. N. Yusril, S. N. Widyaningrum, P. $\mathrm{Al}$ Zukri, and R. A. Tyas, "Pentingnya Implementasi COBIT Dalam Perbankan: Sistematika Literatur Review," in Seminar Nasional APTIKOM, 2019, pp. 394401, [Online]. Available: http://publikasi.dinus.ac.id/index.ph $\mathrm{p} / \mathrm{semnastik/article/view/2638.}$

[3] F. Ajismanto, "Analisis Domain Proses COBIT Framework 5 Pada Sistem Informasi Worksheet (Studi Kasus: Perguruan Tinggi STMIK, Politeknik Palcomtech)," CogITo 
Smart J., vol. 3, no. 2, pp. 207-221, 2017 , doi: 10.31154/cogito.v3i2.75.207-221.

[4] A. R. Naspati, Suprapto, and A. D. Herlambang, "Evaluasi Pengelolaan Sumber Daya Teknologi Informasi (IT Resource Management) dengan Menggunakan Framework COBIT 5 (Studi Kasus: PT. Infomedia Nusantara )," J. Pengemb. Teknol. Inf. dan Ilmu Komput., vol. 2, no. 11, pp. 5384-5393, 2018.

[5] ISACA, COBIT 5: A Business Framework for the Governance and Management of Enterprise IT. USA: ISACA, 2012.

[6] A. F. Wijaya and A. D. Cahyono, "Implementasi Standar Pengelolaan Sumber Daya Teknologi Informasi Guna Mendukung Tata Kelola Teknologi Informasi Di Lembaga Pemerintahan," in Seminar Nasional Teknologi Informasi dan Multimedia, 2016, pp. 6-7.

[7] F. Adikara and Sandfreni, "Optimalisasi Sumber Daya Teknologi Informasi Domain EDM 04.02 Pada Lembaga Pendidikan Dengan Menggunakan Framework COBIT 5," J. Abdimas, vol. 2, no. 2, pp. 18-26, 2016.

[8] Y. D. Hastiti and L. Erawan, "Analisis Tata Kelola Optimalisasi Sumber Daya Sistem Informasi Manajemen Jembatan Timbang (Edm04) Berdasarkan Kerangka Kerja COBIT 5 Pada Dinas Perhubungan Komunikasi Dan Informatika Provinsi Jawa Tengah," Techno COM, vol. 15, no. 2, pp. 170176, 2016.

[9] ISACA, Enabling Processes. 2012.

[10] H. Fryonanda, H. Sokoco, and Y. Nurhadryani, "Evaluasi Infrastruktur Teknologi Informasi Dengan COBIT 5 Dan ITIL V3," JUTI J. Ilm. Teknol. Inf., vol. 17, no. 1, pp. 1-11, 2019, doi:

10.12962/j24068535.v17i1.a717.

[11] H. Kusbandono and D. Ariyadi, "Rekomendasi Perbaikan Infrastruktur TI SMK Berdasarkan Evaluasi Tingkat Kematangan
Framework COBIT 5," J. Appl. Informatics Comput., vol. 2, no. 2, pp. 9-14, 2018, doi: 10.30871/jaic.v2i2.1038.

[12] A. Suradi and S. Wiyanta, "Framework COBIT Untuk Identifikasi Tingkat Kematangan Tata Kelola Teknologi Informasi: Studi Kasus di Fasilkom UNWIDHA," Khazanah Inform. J. Ilmu Komput. dan Inform., vol. 3, no. 1, pp. 38-42, 2017.

[13] ISACA, COBIT 5: Process Assessment Model (PAM): Using COBIT 5. 2013. 